\title{
FORMAÇÃO E ATUAÇÃO NO CURRÍCULO CULTURAL DA EDUCAÇÃO FÍSICA: FIOS QUE SE ENTRELAÇAM
}

\author{
FORMACIÓN Y ACTUACIÓN EN EL CURRICULUM CULTURAL DE LA \\ EDUCACIÓN FÍSICA: HILOS QUE SE ENTRELAZAN
}

\author{
FORMATION AND PERFORMANCE IN THE CULTURAL CURRICULUM OF \\ PHYSICAL EDUCATION: LINES THAT INTERTWINE THEMSELVES
}

\author{
Maria Emília de LIMA ${ }^{1}$ \\ Marcos Garcia NEIRA ${ }^{2}$
}

RESUMO: Tomamos por objetivo do presente estudo analisar como um professor de Educação Física que participou dos cursos de formação oferecidos pela Secretaria Municipal de Educação de São Paulo, no período de 2006 a 2012, significa sua prática pedagógica. Para tanto, realizamos uma etnografia das aulas, recorrendo à observação, entrevistas e análise de documentos. Concluímos que a produção curricular no contexto da escola deu-se, em grande medida, pelo entrelaçamento de significados. Alinhado aos pressupostos do currículo cultural de Educação Física e à política municipal de formação contínua, o educador desenvolveu atividades de ensino consonantes à proposta oficial, estabelecendo um diálogo profícuo entre o repertório dos alunos e os significados atribuídos às práticas corporais tematizadas.

PALAVRAS-CHAVE: Formação de professores. Currículo. Educação física. Cultura.

RESUMEN: Tomamos por objetivo del presente estudio analizar cómo un profesor de Educación Física que participó en los cursos de formación ofrecidos por la Secretaría Municipal de Educación de São Paulo, en el período de 2006 a 2012, significa su práctica pedagógica. Para ello, realizamos una etnografía de las clases, recurriendo a la observación, entrevistas y análisis de documentos. Concluimos que la producción curricular en el contexto de la escuela se dio en gran medida por el entrelazamiento de significados. En conformidad con los presupuestos del currículo cultural de Educación Física ya a la política municipal de formación continua, el educador desarrolló actividades de enseñanza consonantes a la propuesta oficial, estableciendo un diálogo profícuo entre el repertorio de los alumnos y los significados atribuidos a las practicas corporales tematizadas.

PALABRAS-CLAVE: Formación de professores. Curriculum. Educación física. Cultura. ABSTRACT: We have as aim in this study to analyse how a Phisical Education teacher that participated in formation classes offered by São Paulo Municipal Education from 2006 to 2012 gives sense to his pedagogical practice. For this, we made his class etnographic study, by observation, interviews and document studies. We concluded that the curricular production at

1 Universidade de São Paulo (USP), São Paulo - SP - Brasil. Pesquisadora do Grupo de Pesquisas em Educação Física escolar. E-mail: emiliadelima@yahoo.com.br

2 Universidade de São Paulo (USP), São Paulo - SP - Brasil. Professor Titular e coordenador do Grupo de Pesquisas em Educação Física escolar. ORCID <https://orcid.org/0000-0003-1054-8224>. E-mail: mgneira@usp.br 
school context occurred on its great majority, by interweaving of meanings. Following the cultural Phisical Education curriculum theories and the municipal teacher formation courses, this teacher developed teaching activities linked by the oficial proposals, setting up a meaning dialogue between the students repertory and the meaning attributed to the corporal activities topics.

KEYWORDS: Teacher formation. Curriculum. Phisical education. Culture.

\section{Introdução}

O atual cenário de efervescência política, cultural e social demanda novas e às vezes contraditórias funções às escolas. Nesse contexto, buscamos apreender os fios que entrelaçam a prática pedagógica ao emaranhado de orientações curriculares de um professor que afirma atuar segundo os pressupostos da perspectiva cultural da Educação Física ${ }^{3}$.

Não são poucos os documentos curriculares que buscam impactar as escolas através da prescrição da prática pedagógica. Basta verificar que, em alguns estados e municípios, as propostas oficiais se fazem acompanhar de materiais didáticos que descrevem as ações didáticas a serem adotadas, definindo conteúdos, atividades de ensino e instrumentos de avaliação.

Adotando uma postura inversa, a Secretaria Municipal de Educação de São Paulo (SMESP) produziu e publicou, em 2007, Orientações Curriculares (OC) inspiradas na Educação Física cultural. O texto oficial explicita que a definição dos temas de estudo e a organização do trabalho pedagógico cabe ao professor, com a participação dos alunos. Sem discriminar conteúdos de ensino, apresenta como princípios o reconhecimento da cultura corporal da comunidade, a justiça curricular, a docência dialógica, e o entendimento de que as diferenças são culturalmente produzidas.

Deliberadamente, entre 2006 e 2012, a SME-SP tencionou aproximar a ação educativa dos professores dos pressupostos que inspiravam o documento institucional, por meio de cursos, seminários, encontros e reuniões de formação presenciais. A opinião dos professores de Educação Física acerca da proposta foi investigada por Françoso (2011) e Aguiar (2014). O primeiro encontrou dificuldades e facilidades na compreensão do texto, e a segunda percebeu

3 Inspirada no compromisso político dos Estudos Culturais (em sua vertente pós-estruturalista) e pedagógico do multiculturalismo crítico, a Educação Física cultural ou culturalmente orientada atua em prol de uma política da diferença ao tematizar brincadeiras, danças, lutas, ginásticas e esportes oriundos dos diversos grupos que coabitam a esfera social, desnaturalizando os discursos que produzem essas práticas e seus representantes, borrando as fronteiras identitárias e promovendo a negociação de sentidos. (NEIRA, 2011). 
a existência de algumas concepções que se aproximam daquela defendida no documento, enquanto outras se afastam.

Seguindo os rastros dessas pesquisas, partimos do pressuposto de que a prática escolar é uma instância de produção curricular e de formação a partir do "dizer" e "fazer" do professor. Com o intento de examinar os efeitos da política formativa na tessitura das ações curriculares, realizamos uma etnografia das aulas ministradas por um professor que frequentou as atividades organizadas pela SME/SP com vistas a implementar o currículo oficial. Para tanto, observamos o processo pedagógico, entrevistamos o docente e analisamos os registros que ele produziu.

\section{Os fios que entrelaçam o conhecimento}

Uma política curricular busca gerar novas práticas, novas subjetividades profissionais e outras formas de pensar a educação e a formação dos sujeitos. No entender de Silva (2010), o currículo é um dos elementos centrais das reformas educacionais em curso nos mais diversos países. É um importante elemento simbólico do projeto social dos grupos no poder e, apesar da abrangência, produz diferentes efeitos.

As perspectivas científicas do currículo que vigoraram em grande parte do século passado assumiram-no como questão técnica, ocultando a dimensão ideológica. Com tal enfoque, o currículo da escola se baseava na cultura dominante, sendo transmitido através desse código. Visto como prescrição, sustentava a crença de que a especialização e o controle são inerentes ao governo central, às burocracias educacionais e à comunidade universitária.

O pensamento e a estrutura tradicionais do currículo técnico, entretanto, foram criticados pelo "movimento de reconceptualização", nos Estados Unidos, pela "nova sociologia da educação”, na Inglaterra, pela sociologia crítica de Pierre Bourdieu, na França e, no Brasil, pelas obras de Paulo Freire. A crítica à conexão entre a forma como a economia e o currículo se organizavam contribuiu para o questionamento do que se ensinava na escola. Submetidos à transmissão dos conhecimentos elaborados pela ciência moderna, as crianças e jovens terminavam por aprender a "verdadeira" cultura, restando-lhes duas opções: atuavam a partir das expectativas transmitidas ou resistiam ao padrão imposto.

Não obstante, a teoria curricular sofreria uma outra guinada graças ao movimento que se tornou conhecido como "virada cultural". Considerada um campo de disputas pela validação de significados, a cultura foi posicionada no centro dos debates e considerada o principal referente nas explicações dos modos como vemos as coisas e atuamos no mundo (HALL, 1997). 
Logo, o currículo passou a ser visto como um recorte arbitrário da cultura que influencia no posicionamento dos sujeitos, ou seja, institui identidades e diferenças.

Em meio à complexidade dos tempos atuais, em que correntes do pensamento tendem a reconhecer o papel da linguagem na construção da realidade, a necessidade de compatibilizar as características da contemporaneidade com os processos formativos exige uma nova configuração das políticas de formação de professores. Se o que se pretende é construir uma sociedade mais justa, não basta reconhecer a diversidade de culturas presente nas escolas, há que ir além, incorporar seus saberes e problematizar os discursos que exaltam os significados elaborados por determinados grupos, inferiorizando os demais.

Diante do incômodo causado àqueles que se acostumaram a determinar os conhecimentos que preencheriam o percurso escolar, não há como fugir da ideia que o currículo e o próprio conhecimento são campos abertos à disputa e interpretação, nos quais setores divergentes tentam estabelecer sua hegemonia. Afinal, se o currículo for concebido como texto da cultura, suas práticas e discursos acabam por influenciar a produção dos cidadãos e, por consequência, no modelo de sociedade. (LOPES; MACEDO, 2011)

Conceber o currículo como artefato cultural implica refletir sobre o processo produtivo e os sujeitos produtores. Reconhecendo o professor como coautor do texto curricular, consideramos seu potencial para promover mudanças e transformar-se no artesão responsável por desenrolar a trama, fazer escolhas e produzir outros significados, ou seja, tecer o currículo. Nesse sentido, não há como abrir mão de uma política de formação continuada que posicione os docentes como sujeitos do processo.

É sabido que as pressões do mundo do trabalho e a constatação, pelos sistemas de ensino, de "precários" desempenhos escolares, desencadearam reformas curriculares na Educação Básica e no Ensino Superior. Pesquisas como a de Gatti (2008), por exemplo, denunciam que os cursos de formação inicial não propiciam uma adequada base para atuação docente.

Voltada para os docentes em atividade, "é comum que governantes convoquem a formação contínua como 'solução mágica' para melhorar o aproveitamento dos alunos, sempre sob a alegação que os professores são mal formados" (LIPPI, 2009, p. 74). Especialmente nas redes públicas, têm sido implementados projetos formativos que, em muitos casos, não passam de programas compensatórios. Mas, verdade seja dita, também há iniciativas que reconhecem e valorizam os saberes docentes, que passam a ocupar o centro das atenções e intenções.

Nesta perspectiva, o professor é um sujeito que se constitui a partir das experiências vividas, o que significa privilegiar a reflexão sobre a prática, criar redes para trocas de 
experiência e possibilitar sua intervenção direta na própria formação. Consequentemente, já se observa a substituição da formação padrão dirigida por experts acadêmicos que dão soluções a tudo, por uma formação que se aproxima do contexto das instituições educativas e da ideia de que o professorado produz conhecimentos pedagógicos.

Segundo Ibernón (2010), essa proposta toma como referência situações problemáticas da ação cotidiana com o objetivo de responder às necessidades definidas na escola. Tal encaminhamento requer o papel construtivo e criativo dos envolvidos desde o planejamento, valorizando o diálogo, o compromisso e a colaboração. Entretanto, para que mudanças ocorram na ação didática propriamente dita, cabe lembrar primeiramente que as escolas não foram concebidas para favorecer o trabalho colaborativo. E, em segundo lugar, que a prática educativa muda apenas quando o coletivo de professores quer modificá-la e não quando o formador diz. Ao que tudo indica, parece ter sido essa a inspiração das ações formativas realizadas pela SMESP entre os anos 2006 e 2012:

Quadro 1 - Síntese das ações formativas realizadas

2006/2007 - O Grupo Referência (GRESP) ${ }^{4}$ foi instituído com o objetivo de produzir o documento curricular da rede municipal. Para tanto, foram realizadas reuniões para estudo, discussão, redação e incorporação das sugestões dos professores e gestores, mediante consulta às escolas.

2007 - Membros do GRESP coordenaram discussões descentralizadas por região ${ }^{5}$ sobre as OC da SME/SP.

2008 - O GRESP foi ampliado, elaborou as pautas das reuniões e conduziu os encontros formativos nas diferentes regiões da cidade.

2009 - O GRESP conduziu reuniões nos horários coletivos das escolas com o intuito de integrar os professores dos diferentes componentes curriculares.

2009 - O GRESP realizou cursos em todas as regiões, voltados para discussão dos pressupostos teóricos que subsidiam as OC.

2010 - O GRESP realizou cursos para discussão da concepção de Educação Física que inspira as OC e sua relação com as expectativas de aprendizagem.

2010 - O GRESP realizou um seminário para acolhimento dos professores de Educação Física ingressantes através do concurso daquele ano.

2011 - Cada participante do GRESP convidou um colega professor de Educação Física e, a partir de um trabalho colaborativo, problematizaram e qualificaram a prática pedagógica nas unidades educacionais.

2011 - O GRESP realizou cursos para discussão dos pressupostos metodológicos que caracterizam as OC.

2011 - O GRESP realizou reuniões formativas com um coordenador pedagógico de cada escola da rede municipal com vistas a discutir as OC.

2011 - O GRESP realizou um seminário para acolhimento dos professores de Educação Física ingressantes através do concurso daquele ano.

2012 - O GRESP organizou e realizou cursos em que se discutiram as práticas corporais enquanto textos da cultura. 2012 - O GRESP organizou e realizou um seminário com professores e gestores educacionais para debater o ensino de Educação física pautado nas OC.

Fonte: Autores

4 Coletivo formado por professores da rede municipal e dois assessores externos.

5 Na época, a SME/SP se subdividia em 13 Diretorias Regionais de Educação.

RIAEE - Revista Ibero-Americana de Estudos em Educação, Araraquara, v. 14, n. 1, p. 208-221, jan./mar., 2019. E-ISSN: $1982-5587$. 
A análise das pautas das reuniões e dos programas dos cursos ministrados permitiu detectar a prioridade ao debate dos pressupostos teórico-metodológicos contidos nas OC. A metodologia utilizada, bem como o protagonismo de professores da própria rede, levou-nos a identificar a preocupação em situar o docente (e seus conhecimentos) no centro de todo o processo. Ademais, tal iniciativa mostrou-se fiel à concepção política e pedagógica que subsidia a Educação Física cultural quando traz como pressuposto a valorização dos saberes de todos os envolvidos na dinâmica curricular: professores, gestores, estudantes e comunidade educativa.

Nossas análises corroboram a interpretação de Aguiar (2014, p. 87), para quem as propostas formativas de SME/SP nesse período "não se organizavam e visavam, como geralmente encontramos na área, à realização de cursos voltados para a transmissão de uma série de atividades ou mesmo à execução de aulas práticas". Tendo por base o documento oficial, as pautas das formações voltavam-se à compreensão da epistemologia e da ação didática perspectivadas pelo currículo municipal.

\section{Desembaraçando um emaranhado de fios}

Sem a pretensão de esgotar a discussão, durante o ano letivo de 2013, realizamos uma etnografia das aulas de um professor que participou dos cursos de formação oferecidos pela SME-SP, com o intuito de analisar como o docente significa sua prática pedagógica. O educador respondeu positivamente ao convite enviado a todos que ingressaram na rede municipal através dos concursos realizados em 2010 e 2011, e haviam participado de ao menos duas entre as várias ações formativas oferecidas.

Considerando que qualquer educador se encontra enroscado nos fios que ligam o seu fazer ao contexto da escola e às normatizações da rede de ensino onde atua, para mapear o contexto da pesquisa vivenciamos o ambiente da escola, percorrendo o horário do intervalo dos alunos e conversamos com alguns professores e funcionários. Ao mesmo tempo, procedemos à análise dos documentos elaborados pelo docente, em específico, o Livro da Classe ${ }^{6}$.

Durante o período de permanência na escola, registramos em vídeo todas as atividades correspondentes à tematização do boliche e do jogo de taco. Nossa mirada recaiu sobre a tessitura do currículo, isto é, focamos os modos como o professor propunha as atividades; as interações com os alunos; os temas abordados e as respostas (e os silêncios) dos estudantes.

6 Trata-se de um caderno em que o professor participante do estudo registrava suas ações e reflexões. 
Também registramos em diário de campo elementos que nos permitiram contextualizar cada aula filmada.

Buscando melhor interpretar os resultados, inúmeras vezes assistimos aos vídeos gravados e selecionamos os trechos das aulas que esboçavam relações com a proposta curricular oficial, sem que o professor soubesse desse recorte. Os registros do diário de campo contribuíram para definir critérios de seleção dos excertos das filmagens, os quais, seguindo as recomendações de Lankshear e Knobel (2008), foram utilizados durante as entrevistas com o docente, enquanto dispositivos de evocação.

Foi possível observar que os fios oriundos de contextos diversos foram tramados a várias mãos para produção do tecido/texto curricular de Educação Física. Identificamos que o professor estabeleceu vários pontos de contato com as orientações municipais explicitadas nos documentos oficiais e nas propostas formativas. Considerando-o artesão responsável pela produção no contexto da prática pedagógica, inferimos dois processos por ele utilizados durante a tessitura: a "incorporação dos nós” e o “desembaraçamento de fios e novos entrelaçamentos".

\section{Incorporação dos nós}

No âmbito da formação inicial, segundo informou, o professor acessou os discursos da psicomotricidade e do desenvolvimento motor, muito embora as atividades práticas tenham se resumido ao ensino das técnicas esportivas. A saber, a proposta psicomotora "tem um caráter utilitarista, tomando o corpo como objeto passível de aperfeiçoamento" (BORGES, 2017, p. 845), e no currículo desenvolvimentista, "o intuito é atingir o patamar de eficiência e precisão dos movimentos" (BORGES, 2017, p. 846). Em se tratando de propostas acríticas, possivelmente a docência em Educação Física tenha sido significada numa vertente performática calcada em atividades fragmentadas e descontextualizadas, com foco na cultura corporal dominante.

Somente quando ingressou na rede municipal de São Paulo o professor tomou contato com a perspectiva cultural do componente, que proporciona aos educandos situações de leitura e produção das práticas corporais disponíveis na sociedade, fazendo valer o repertório dos grupos subjugados. Exposto ao processo de formação nessa vertente, o professor empenhou-se em traduzir discursos até então desconhecidos. Ou seja, coube-lhe desatar nós, puxar fios, reorganizar tramas e produzir o novo (para ele) fazer curricular no contexto da prática. 
Daí resultou uma variedade de atividades didáticas de caráter flexível. A análise da transcrição das observações permite identificar momentos de planejamento, desenvolvimento das atividades de ensino, avaliação e replanejamento.

Iniciamos a problematização do tema boliche. Para tanto, os alunos dividiramse em grupos e registraram num papel as regras do boliche que conheciam. A vivência acontecerá baseada nessas regras (LIVRO DA CLASSE, 22/08/13).

Para disponibilizar aos alunos as informações de maneira organizada, por diversas ocasiões, o professor registrou na lousa aspectos importantes dos diálogos travados. Ao mesmo tempo, um aluno colaborador copiava o tex to em seu caderno. Organizavam-se assim diferentes encaminhamentos para ações coletivas como as vivências ou mesmo roteiros de pesquisas.

É interessante pontuar que um dos vídeos $^{7}$ produzidos para apoiar a formação continuada da SME/SP trata justamente da relevância do professor organizar junto com os alunos, escrevendo no quadro ou em um cartaz, as questões importantes, as representações veiculadas, as principais dúvidas, etc. Esse material aponta para a necessidade do professor produzir e conduzir as atividades didáticas, elaborando um roteiro com base nos conhecimentos que precisam ser levantados e estudados sem perder de vista o contexto escolar. A retomada da trajetória curricular foi assim justificada:

Os registros que eu li foram os registros que aconteceram durante a aula. Os que eu já tinha anotado. Nós retomamos esses registros para discussão. Para que pudéssemos discutir aqueles acontecimentos. Para que eles pudessem explicar o que estava acontecendo naquele momento. Com a ideia de dar o prosseguimento no trabalho. Para manter a continuidade. Então os registros auxiliam principalmente nesse processo de continuidade aos estudos. Não tem nada definido, rígido. Conforme os registros que vão surgindo nós vamos elaborando o processo de estudo (EDUARDO).

Um dos focos da proposta curricular da SME-SP, no período investigado, era o desenvolvimento da competência leitora e escritora dos alunos, assim, segundo documento oficial, à Educação Física escolar cabe proporcionar aos alunos experiências que viabilizem tanto a prática das manifestações corporais quanto a "reflexão crítica acerca das diversas formas de representação cultural veiculadas pelas brincadeiras, lutas, esportes, ginásticas e danças" (SÃO PAULO, 2007, p. 36). De certa forma, o professor organizou atividades de ensino para possibilitar a leitura, interpretação e a análise dos códigos relativos ao tema em estudo.

7 Vídeo 27 - Artes e Educação Física Seminário IV - Ampliação dos conhecimentos. Vídeo produzido pela SMESP e a Fundação Padre Anchieta com o objetivo de divulgação e de formação dos professores da rede de educação paulistana. 
Os alunos começaram a explicar as regras do jogo. Tentamos sistematizar estas regras para realizarmos a vivência. No entanto, o diálogo foi meio tumultuado, comprometendo o entendimento do jogo. Tentamos vivenciar o jogo da maneira explicada por alguns alunos da classe (LIVRO DA CLASSE, 08/11/13)

Fizemos a leitura de um vídeo mostrando a prática esportiva do boliche. Atentamo-nos para as técnicas de lançamento, as vestimentas utilizadas e as regras do jogo. Os alunos registraram tudo com vistas à elaboração de um relatório que será apresentado após a visita à pista de boliche (LIVRO DA CLASSE, 20/09/13).

O professor retomou as questões que nortearam a observação por ocasião da visita ao boliche: questão 1 - identificar aspectos discutidos nas aulas, conteúdos levantados, coisas que foram estudadas. Anotou na lousa os comentários dos alunos: tipos de jogadas, características dos materiais, pessoas que frequentam o espaço; regras observadas; formas de pontuação. Na lousa foi anotando a fala de todos os alunos (DIÁRIO DE CAMPO, 26/09/13).

Nesta aula nós estávamos retomando alguns conteúdos que nós vimos nas aulas anteriores. No caso, alguns códigos sociais, alguns códigos culturais que estão presentes no boliche. [E quais seriam?] A questão dos materiais, dos artefatos culturais que são usados por eles. As vestimentas, a roupa. Os materiais em si. A bola, porque a bola faz aquele tipo de curva. Porque a pista tem determinada forma (EDUARDO).

Primeiramente, convém salientar que a ação do currículo cultural consiste numa mobilização de recursos e conhecimentos múltiplos que estabelecem relações de diversas naturezas. Além disso, observamos que as atividades de ensino promovem a leitura da gestualidade e a reconstrução da prática corporal tematizada. Tal constatação pode sugerir um efeito da política formativa, uma vez que o assunto fora trabalhado nos cursos ofertados pela SME/SP, conforme se observa nos objetivos anunciados em Diário Oficial:

- Elucidar os fundamentos teóricos e metodológicos que subsidiam o Documento Orientações Curriculares e Expectativas de Aprendizagem de Educação Física;

- Produzir situações didáticas que permitam aos estudantes ampliar suas análises e vivências com relação às práticas corporais;

- Reconhecer a avaliação como ação fundamental para a construção de um currículo de Educação Física pautado na perspectiva cultural. (SÃO PAULO, 2012, p. 38).

Apesar dos esforços observados, por vezes, a realidade obstaculiza uma atitude curricular coerente. O próprio professor Eduardo parece não ter desatado esse "nó" quando "finalizou a aula dizendo que não vai ser possível esgotar todos os conteúdos relacionados a 
esta manifestação corporal por conta das atividades de finalização do ano letivo" (DIÁRIO DE CAMPO, 05/12/13).

\section{Desembaraçamento dos fios e novos entrelaçamentos}

Durante a tematização do boliche e do jogo de taco, a reflexão sobre os efeitos do trabalho nos alunos e a necessidade de replanejar as atividades de ensino possibilitaram, aos poucos, que os fios fossem desembaraçados e novamente entrelaçados.

Em conformidade com as $\mathrm{OC}$, o processo educativo não se deu em etapas estanques e lineares, ao contrário, com base na análise dos próprios registros, o professor fomentou o debate, avaliou continuamente o percurso realizado, como também possibilitou condições de aprofundar e ampliar os conhecimentos da turma.

Fizemos a leitura das pesquisas realizadas para obter as respostas das dúvidas que surgiram durante a saída pedagógica. A aluna Evelyn fez a leitura de sua pesquisa e eu li as respostas fornecidas por um praticante da atividade. Fizemos uma nova e breve vivência do jogo (LIVRO DA CLASSE, 04/10/13).

Antes de apresentar um vídeo sobre o jogo, o professor solicitou aos alunos que identificassem os aspectos já discutidos em aula. No final da apresentação, perguntou: deu para reconhecer alguma coisa? Os alunos respondem: bola perdida, cruzar o taco. O professor insistiu: quanto ao lugar que joga a bolinha deu para ver algo diferente? Nenhuma resposta. O professor voltou ao vídeo e perguntou: a pessoa pode jogar do lugar onde pegou a bolinha ou deve se posicionar atrás da garrafa? O Alexandre respondeu que na rua dele sempre joga atrás da garrafa. $\mathrm{O}$ educador, mais uma vez, questionou: como fica o nosso jogo aqui na escola? Os alunos decidiram experimentar a proposta do Alexandre (DIÁRIO DE CAMPO, 05/12/13).

A intenção era realmente dar um novo significado para o jogo. Fazer algumas modificações porque as condições que nós tínhamos de material, de espaço e do grupo eram diferentes do jogo na rua. Então nós fizemos uma proposta. A partir do diálogo, eles propuseram modificações, alterações, propostas para que nós pudéssemos fazer a vivência na escola com as condições que nós tínhamos (EDUARDO).

Para discutir o contexto histórico do boliche, organizou exposições orais com apoio de recursos elaborados a partir de pesquisas sobre o assunto. As aulas foram desenvolvidas em ambientes variados, desmistificando a exclusividade do uso da quadra poliesportiva. $\mathrm{O}$ professor também preparou atividades sala de informática mediante o acesso à internet. Observe-se que os cursos de formação promovidos pela SME/SP destacaram e subsidiaram a relevância da pesquisa sobre as práticas corporais, além da leitura de textos de diferentes gêneros, enquanto atividades para aprofundar os conhecimentos sobre a prática corporal. $\mathrm{O}$ 
mesmo se pode dizer das atividades de ensino em que a negociação de significados deu-se pela hibridização discursiva.

A leitura do vídeo acabou confrontando com alguns significados que as crianças atribuíam e a algumas coisas que eles conheciam sobre o jogo, com explicações de outros grupos. E acabou conflitando os significados. Então, isso deu para perceber na fala do Alexandre que ele falou que na rua dele ele jogava de um jeito que era totalmente diferente. Totalmente não, mas algumas coisas daquilo que nós vimos no vídeo. E a partir do confronto também tentamos organizar nosso jogo (EDUARDO).

Nós tínhamos ido para a pista de boliche numa das aulas anteriores e as crianças tiveram algumas dúvidas sobre algumas coisas que apareceram na pista: as setas, as linhas, as posições dos pinos. Na aula anterior eu fui registrando essas dúvidas. Numa outra aula eles fizeram pesquisas para tentar sanar estas dúvidas. Eu também consegui entrar em contato com um praticante de boliche e ele respondeu algumas coisas sobre os sapatos utilizados, as linhas e as setas (EDUARDO).

O professor promoveu assistência a um vídeo com o objetivo de retomar a história do boliche. Fez várias interrupções para acrescentar informações que julgava necessárias. Ao ouvir a informação que o jogo de boliche sofreu algumas modificações ao chegar aos Estados Unidos, um dos alunos disparou o seguinte comentário: 'os Estados Unidos mudam tudo mesmo'. Questionou os alunos a respeito dos locais de montagens de pistas de boliche em nossa cidade. Um aluno disse que estão nos mercados. Outro corrigiu dizendo que estão nos hipermercados e ainda uma aluna apontou para os Shoppings Centers. O professor aproveitou a oportunidade e questionou a respeito da classe social representativa desse esporte. (DIÁRIO DE CAMPO, 17/10/13).

Canen e Oliveira (2002) explicam que as atividades pautadas na pedagogia cultural cruzam fronteiras, reconhecem a provisoriedade dos saberes e ajudam a superar congelamentos identitários. Tanto que as discussões que se sucederam às narrativas estimularam a reelaboração das regras e a adaptação dos materiais para a vivência do jogo. Para efetivar o processo de leitura, escrita e reescrita das manifestações abordadas, em plena consonância com o currículo municipal, os pontos de vista dos alunos e seus familiares foram valorizados, assim como os argumentos extraídos dos materiais utilizados. O professor promoveu debates, vivências e, invariavelmente, sistematizou ideias, acordos e conceitos principais. Tudo isso leva a crer que os estudantes reconstruíram suas formas de ver o boliche e o jogo de taco.

Por outro lado, nota-se que durante a tematização do boliche, o fator relativo à classe social foi destacado, porém, conforme sugerem as OC, um esforço maior seria necessário para problematizar os marcadores sociais que perpassam a prática corporal. Temos que reconhecer que a proposta formativa da SME/SP, embora tenha propiciado reflexões sobre a concepção de Educação Física presente no documento oficial, pode não ter logrado êxito no fomento a uma 
compreensão mais profunda da proposta, sobretudo no que concerne ao questionamento de como as relações de poder atuam no modo como representações das práticas corporais são elaboradas e disseminadas. Essa suspeita advém da abordagem pautada na mera constatação dos fatos sem questionar suas razões.

O Eduardo propôs a discussão sobre a história do boliche. Para tanto reproduziu uma narrativa histórica a partir de alguns textos pesquisados. Uma cópia impressa foi entregue a cada aluno para prosseguirem com a leitura compartilhada. Antes de iniciarem a leitura o professor apresentou duas questões - boliche é esporte para rico? Por que o boliche começou a adentrar os shoppings? - apesar do texto informar que durante algum tempo o boliche possuía conotação religiosa, sendo, inclusive, proibido pela Igreja

Professor: em 1982 foi montada a primeira pista automática no Morumbi shopping. Morumbi é um bairro do quê?

Alunos: um bairro para ricos.

Professor: um bairro onde moram as pessoas de classe social alta. A primeira pista foi montada num bairro de pessoas ricas. Por que não veio para cá, no shopping Bom Sucesso?

Aluna: o Bom Sucesso é Shopping de pobre.

Aluno: quem é pobre aqui? Eu sou. (DIÁRIO DE CAMPO, 18/10/13).

Assim conduzida, a conversa pode ter reforçado estereótipos, deixando a impressão que o boliche é uma prática dos privilegiados, mesmo que a turma tenha vivenciado o jogo por várias semanas. De qualquer maneira, não há como negar que o professor promoveu atividades que contribuíram para qualificar a leitura das manifestações tematizadas, bem como a sua produção, tal como as OC anunciam a função da Educação Física. Embora tenham deixado alguns fios embaraçados, é notório que as atividades de ensino realizadas exprimem uma prática pedagógica que entrelaça significados alusivos às práticas corporais com discursos de cunho econômico e histórico.

\section{Arremate final}

A análise das observações, entrevistas e documentos permite afirmar que o professor desenvolveu uma metodologia dialógica, levando em conta os saberes, os interesses e os desejos dos alunos. As vivências corporais que organizou foram entremeadas por leituras e interpretações, propiciando novas produções. Também elaborou e desenvolveu atividades de ensino para o reconhecimento dos significados atribuídos por diferentes grupos sociais às manifestações tematizadas. No entanto, avaliamos que nem sempre as atividades de ensino desenvolvidas possam ter contribuído para desconstruir o conjunto de verdades materializadas nos discursos que permeiam as práticas corporais. 
Se, por um lado, os dados analisados oferecem indícios suficientes para afirmar uma docência da Educação Física culturalmente orientada, mesmo que não seja na sua totalidade, por outro, é importante lembrar que durante a formação inicial o professor acessou exclusivamente as propostas convencionais ${ }^{8}$ do componente. Isto posto, nos parece evidente que a política formativa da SME/SP influenciou o fazer pedagógico observado, ratificando o entendimento de que, ao ter significado ao seu modo o currículo cultural, o docente emaranhou diversos fios, tornando-se seu próprio artesão.

\section{AGRADECIMENTOS: CNPq.}

\section{REFERÊNCIAS}

AGUIAR, C. A. Educação Física no município de São Paulo: aproximações e distanciamentos com relação ao currículo oficial. 2014. 187f. Dissertação (Mestrado em Educação). Universidade de São Paulo, São Paulo, 2014.

BORGES, C. C. O. Políticas de currículo da Educação Física e a constituição de sujeitos. Movimento, Porto Alegre, v. 23, n. 3., p. 841-854, jul./set. de 2017.

CANEN, A.; OLIVEIRA, A. M. A. Multiculturalismo e Currículo em Ação: um estudo de caso. Revista Brasileira de Educação, Rio de Janeiro, v. 21, p. 61-74, set./dez. 2002.

FRANÇOSO, S. Cruzando fronteiras curriculares: a Educação Física no enfoque cultural na ótica de docentes de escolas municipais de São Paulo. 2011, 221f. Dissertação (Mestrado em Educação: Currículo) Pontifícia Universidade Católica de São Paulo, 2011.

GATTI, B. A. Análise das políticas públicas para formação continuada no Brasil, na última década. Revista Brasileira de Educação. Rio de Janeiro, v. 13 n. 37 jan./abr. p. 57-70, 2008.

IBERNÓN, F. Formação continuada de professores. Porto Alegre: Artmed, 2010.

LANKSHEAR, C.; KNOBEL, M. Pesquisa pedagógica: do projeto à implementação. Tradução de Magda França Lopes. Porto Alegre: Artmed, 2008.

\section{LIPPI, B. G. Formação contínua de professores de educação física no Estado de São} Paulo: quais as políticas em jogo? 2009. 217 f. Dissertação (Mestrado em Educação). Faculdade de Educação. Universidade de São Paulo. São Paulo: FEUSP, 2009.

LOPES, A. C.; MACEDO, E. Teorias de Currículo. São Paulo: Cortez, 2011.

NEIRA, M. G. Educação Física. São Paulo: Blucher, 2011.

8 No entender de Neira e Nunes (2009), os currículos psicomotor e desenvolvimentista correspondem a propostas tradicionais da Educação Física. 
NEIRA, M. G.; NUNES, M. L. F. Educação Física, currículo e cultura. São Paulo: Blucher, 2009.

SÃO PAULO (SP). Secretaria Municipal de Educação. Orientações Curriculares e Proposição de Expectativas de Aprendizagem para o Ensino Fundamental: ciclo II Educação Física. São Paulo: SME/DOT, 2007.

SILVA, T. T. O currículo como fetiche: a poética e a política do texto curricular. Belo Horizonte: Autêntica, 2010.

\section{Como referenciar este artigo}

LIMA, M. E. de.; NEIRA, M. G. Formação e atuação no currículo cultural da Educação Física: fios que se entrelaçam. Revista Ibero-Americana de Estudos em Educação, Araraquara, v. 14, n. 1, p. 208-221, jan./mar., 2019. E-ISSN: 1982-5587. DOI: 10.21723/riaee.v14i1.10888

Submissão: $12 / 01 / 2018$

Revisões requeridas: 20/05/2018

Aprovação final: 23/08/2018 